\title{
Medical savings accounts: Singapore's non-solution to healthcare costs
}

\author{
One small part of a complex patchwork of funding
}

\author{
Martin McKee professor of European public health ${ }^{1}$, Reinhard Busse professor of healthcare \\ management $^{2}$
}

${ }^{1}$ London School of Hygiene and Tropical Medicine, London WC1H 9SH, UK; ${ }^{2}$ Technische Universität, Berlin, Germany

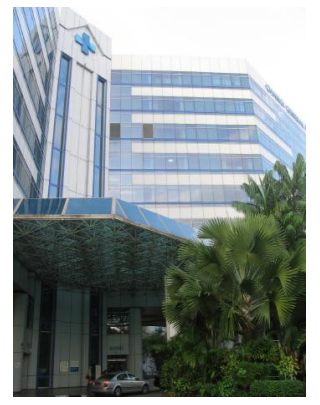

Not a model worth emulating

Because of the obvious failings of the American health system, health policy analysts in the United States have traditionally looked abroad for inspiration. ${ }^{1}$ William Haseltine, president of ACCESS Health International, is among the latest to do so. Inspired by a 2010 lecture on the health system in Singapore, he searched for a book that would provide him with a detailed explanation of how it worked. Finding that none existed, he set out to fill the gap. The result is a short, highly readable book whose title, Affordable Excellence, summarises accurately, if somewhat uncritically, his judgment on Singapore's achievements. ${ }^{2}$ In it, he documents how Singapore has managed to contain costs while ensuring access to healthcare and achieving health outcomes that are as good, and in many cases better, than those in other developed countries.

One reason why Singapore has attracted international interest is its unique system of healthcare financing, with the concept of the medical savings account (Medisave) at its core. ${ }^{3}$ Under this system, all people are responsible for their own healthcare and that of their family. Money is saved into an account from which they can draw when necessary. Workers and their employers (and since 1992 the wealthier self employed) are mandated to contribute a tax-free proportion of their income, which reduces with increasing age, into a designated account that they can use to pay for care when needed. Funds can be shared among members of the immediate family, and any money left over at death is inherited by surviving family members.

However, there are restrictions on what the money can be spent on. Initially only inpatient stays in the most basic level of Singapore's hierarchy of hospital wards were covered, but the system then expanded to include outpatient treatment. More recently, mental illness and some specified preventive interventions, such as mammography and certain immunisations, have been included. However, payments are subject to deductibles and co-payments.

Not surprisingly, this concept is attractive to those who most vocally advocate for individual responsibility for health, who reject the social solidarity that underpins European health systems and call for a radical shrinking of the state (and by extension their tax bills). ${ }^{45}$ Yet, as Haseltine notes, the medical savings account is only one small element of Singapore's health system, even if it is the one that has attracted most attention. It has never accounted for more that $10 \%$ of total health expenditure. As he shows, it only works by being wrapped up in a complex network of mechanisms that compensate for its failure to deal with the fundamental challenge in delivering universal healthcare ${ }^{6}$ - those in most need of healthcare, typically older and poorer people, are least able to pay for it. Firstly, Medisave accounts are supplemented by a variety of government contributions, such as the "grow and share package," which makes direct payments into accounts of younger people on low and middle incomes, and a scheme to support older lower paid workers.

Secondly, the cost of care is limited by major subsidies to hospitals - up to $80 \%$ of the cost of inpatient treatment - on top of other payments for capital expenditure. There are also strict controls on what hospitals can do and what they can charge, including limits on purchase of advanced technology. This reflects the lessons learnt from a move to give hospitals more autonomy in the 1980s, in the misguided belief that competition would reduce costs. 
Thirdly, two other funds fill the gaps left by Medisave. Medishield covers what is termed "catastrophic health expenditure" but which, in reality, includes all long term treatment that would soon drain Medisave accounts. Since 2002, this has been supplemented by the Eldershield scheme, which provides cover for older people with long term disability. Finally, for those who have no remaining funds, there is a safety net, called Medifund, which gives priority to older people whose Medisave funds have become depleted. This is paid for from the income of a large endowment fund created by the government. Even with these measures, there are concerns about the system's ability to fund care for an ageing population. ${ }^{78}$

All of these interventions create a system in which, despite a high level of out of pocket spending - almost two thirds of total health expenditure - ${ }^{9}$ poor people are relatively well protected. This is not quite the model of individual responsibility that it is so often portrayed to be.

Given the many specificities of Singapore, it is not surprising that the medical savings account has not found success elsewhere. In the US, such schemes lack the many safeguards in place in Singapore and thus have limited use. The Commonwealth Fund argued that "encouraging people to join such health plans will exacerbate some of the very maladies that undermine our healthcare system's ability to perform at its highest level." ${ }^{10}$ An attempt to implement the Medisave model in another large Asian city, Shanghai, failed. ${ }^{11}$

Most health systems are shaped by the conditions in place when they were created, and Singapore's is no exception. The Medisave scheme is part of a larger insurance scheme, the Central Provident Fund, created in 1955, during British rule, to provide old age benefits. The features of that fund, created for an entirely different purpose, have been carried forward into the funding of healthcare. As Haseltine notes, Singapore has managed to make it work, but only as one small part of an extremely complicated system involving extensive government intervention. This is a point that is lost among those politicians and think tanks engaged in the current campaign to denigrate the English NHS when they advocate medical savings accounts as a solution here. ${ }^{12}$
Competing interests: We have read and understood the BMJ policy on declaration of interests and declare the following interests: None.

Provenance and peer review: Commissioned; not externally peer reviewed.

1 Nolte E, McKee CM. In amenable mortality - deaths avoidable through health care-progress in the US lags that of three European countries. Health Affairs 2012;31:2114-22.

2 Haseltine WA. Affordable excellence: the Singapore healthcare story. Brookings Institution Press, 2013.

3 Hsiao WC. Medical savings accounts: lessons from Singapore. Health Aff (Millwood) 1995;14:260-6; discussion 77-9.

4 Ramsay C, Butler E. Medical savings accounts: and now .... a medical ISA? Adam Smith Institute, 2001.

5 Green D. How does the rest of the world manage? Civitas, 2001

6 Kin LM. Shifting the burden of health care finance: a case study of public-private partnership in Singapore. Health Policy 2004;69:83-92.

7 Chia NC, Tsui AK. Medical savings accounts in Singapore: how much is adequate? $J$ Health Econ 2005;24:855-75.

8 George PP, Heng BH, De Castro Molina JA, Wong LY, Wei Lin NC, Cheah JT. Self-reported chronic diseases and health status and health service utilization--results from a community health survey in Singapore. Int J Equity Health 2012;11:44.

9 Wagstaff A. Health systems in East Asia: what can developing countries learn from Japan and the Asian tigers? Health Econ 2007;16:441-56.

10 Collins SR. Health savings accounts and high-deductible health plans: why they won't cure what ails US health care. Invited testimony to the Subcommittee on Health, Committee on Finance, United States Senate hearing on "Health Savings Accounts: The Experience So Far." Commonwealth Fund, 2006. www.commonwealthfund.org/Publications/ Testimonies/2006/Sep/Health-Savings-Accounts-and-High-Deductible-Health-Plans-Why-They-Wont-Cure-What-Ails-U-S--Health-C.aspx.

11 Dong W. Can health care financing policy be emulated? The Singaporean medical savings accounts model and its Shanghai replica. J Public Health (Oxf) 2006:28:209-14.

12 Spiers J. Individual health savings accounts will improve access and performance. Institute of Economic Affairs, 2008.

Cite this as: BMJ 2013;347:f4797

\section{Related links \\ bmj.com/archive}

Previous articles by Martin McKee

- In search of social equipoise (2013;347:f4016)

- Will austerity cuts dismantle the Spanish healthcare system? (2013;346:f2363)

- Health policy in Europe: Factors critical for success (2013; 346:f533)

- The future of England's healthcare lies in the hands of competition lawyers $(2013 ; 346: f 1733)$

(c) BMJ Publishing Group Ltd 2013 